Check for updates

Cite this: RSC Adv., 2019, 9, 17318

\title{
Improvement of PEDOT:PSS linearity via controlled addition process
}

\author{
Hongjoo Lee, Youngno Kim, Hangyeol Cho, Jin-geun Lee and Jung Hyun Kim (D)*
}

Poly(3,4-ethylene dioxythiophene):poly(styrene sulfonate) (PEDOT:PSS), which is a conductive polymer, has gained immense attention as a next-generation transparent electrode. However, in order to realize its practical application, it is imperative that its optical and electrical properties should be improved. Generally, acid dopants are added to improve optical and electrical properties. In this study, however, we replaced the batch process used for manufacturing PEDOT:PSS with a controlled addition process to improve its optical and electrical properties efficiently without additional additives and processes. In this process, the rate of polymerization and the structure of the product could be regulated by controlling the amount of monomer and catalyst. Moreover, we investigated the efficiency of the controlled addition process both theoretically and experimentally. The proposed approach was used to increase the linearity of PEDOT and the proportion of PEDOT attached to the PSS chain to improve transmittance by $6.2 \%$ (73 to $79.2 \%$ at $100 \mathrm{ohm}$ ) and conductivity by $39.68 \%\left(446\right.$ to $623 \mathrm{~S} \mathrm{~cm}^{-1}$ ). It was determined that the properties of PEDOT:PSS could be improved using the proposed method during the polymerization process.

Received 24th April 2019 Accepted 28th May 2019

DOI: 10.1039/c9ra03040a

rsc.li/rsc-advances photovoltaics (OPVs). ${ }^{16}$ Therefore, it is considered as a potential organic electronic material.

PEDOT:PSS exhibits a complex structure, in which electrically conducting PEDOT $^{17,18}$ and electrically insulating PSS are combined via coulombic interactions. ${ }^{19}$ PEDOT shows hydrophobicity and poor stability. In contrast, PSS improves the performance and stability of PEDOT:PSS by acting as a dopant and dispersing agent. ${ }^{20,21}$ Since PEDOT is electrically conducting, the amount of PEDOT attached to the PSS chain affect the electrical conductivity of PEDOT:PSS.

In general, studies have been introduced to add acid dopants to enhance the optical and electrical properties of PEDOT:PSS. However, the use of additional acid dopants can result in additional costs and therefore inefficiency in price.

We focused on improving the electrical and optical characteristics of PEDOT:PSS by replacing the batch and vapor phase polymerization processes ${ }^{22,23}$ with a modified process, called controlled addition process (CAP). Approach for improving the electrical conductivity and transmittance of PEDOT:PSS based on process modification only, without using additional additives. Therefore, this is efficient in terms of process and price. ${ }^{24}$

We designed our experiments based on mathematical theory. The experiment parameters reflect the settings determined by mathematical theory. We compared the structure of PEDOT:PSS films polymerized via the batch and CAP. The electrical and optical properties of the PEDOT:PSS films were also compared. The mathematical theory and experimental results showed that PEDOT:PSS polymerized via CAP can be used efficiently in terms of process and cost for the 
polymerization of PEDOT:PSS available for organic transparent electronic devices. ${ }^{25,26}$

\section{Experimental}

\section{Materials}

PSS, EDOT (97\%), sodium persulfate $\left(\mathrm{Na}_{2} \mathrm{~S}_{2} \mathrm{O}_{8} ; 98 \%\right)$, iron(III) sulfate hydrate $\left(\mathrm{Fe}_{2}\left(\mathrm{SO}_{4}\right)_{3} ; 97 \%\right)$, and dimethyl sulfoxide (DMSO; 98\%) were purchased from Sigma-Aldrich. The ion exchange resins (anion and cation) were purchased from Samyang Co.

\section{Synthesis and analysis of PEDOT:PSS via the controlled addition process}

We performed the synthesis with EDOT, $\mathrm{Fe}_{2}\left(\mathrm{SO}_{4}\right)_{3}$, and $\mathrm{Na}_{2} \mathrm{~S}_{2} \mathrm{O}_{8}$ using the Baytron P procedure. The PEDOT:PSS ratio was $1: 2.5$ (according to Clevios PH1000). The reaction temperature was maintained at $10{ }^{\circ} \mathrm{C}$. A total reaction time of $18 \mathrm{~h}$ is required for batch processing which was divided into two and three intervals (Scheme 1), and the reaction was performed in an argon atmosphere. After the reaction was completed, the ion exchange resin was added to remove impurity ions and the reaction temperature was increased to $20{ }^{\circ} \mathrm{C}$. The PEDOT:PSS solution for analysis was prepared by adding $5 \mathrm{wt} \%$ of DMSO and $0.1 \mathrm{wt} \%$ of the surfactant. After removing the excess particles using a $5 \mu \mathrm{m}$ syringe filter, spin coating was performed for $30 \mathrm{~s}$ and the resulting film was annealed at $150{ }^{\circ} \mathrm{C}$ for $2 \mathrm{~min}$.

\section{Characterization}

The synthesis time was calculated based on the complete conversion time of PEDOT:PSS as measured using UV-Vis-NIR spectrophotometry (JASCO Corporation, V-650). The PEDOT:PSS structure was examined using X-ray photoelectron spectroscopy (XPS; Thermo U.K., K-alpha) using monochromated $\mathrm{Al} \mathrm{K} \alpha \mathrm{X}$-ray radiation, Raman spectroscopy (Horiba

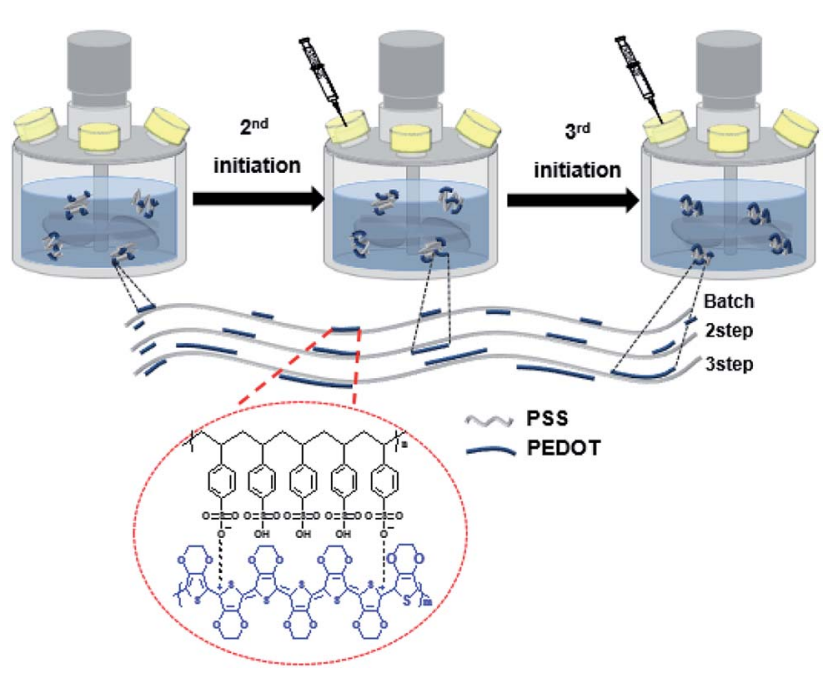

Scheme 1 Polymerization via the controlled addition process, in which the monomer and catalyst were divided into two and three portions. The chemical structures of PEDOT (blue) and PSS (black) are shown.
Jobin Yvon, LabRam Aramis) using a $633 \mathrm{~nm} \mathrm{He-Ne} \mathrm{laser} \mathrm{as} \mathrm{the}$ excitation source and high-resolution X-ray diffraction (HRXRD; Rigaku, SmartLab). To evaluate the electrical properties of PEDOT:PSS, its surface resistance was measured using the four-point probe method (Napson, RT-70/RG-5) and a film thickness surface profiler (Bruker, Dektak XT Stylus profiler). The transmittance of the PEDOT:PSS film was measured using a colorimeter (Nippon Denshoku, COH 400).

\section{Results and discussion}

\section{Process design for polymerization rate control}

In this study, we modified the conventional (batch reactor) PEDOT:PSS polymerization by controlling the reaction rate using a controlled addition process. Factors considered to design the process are temperature and the amount of catalyst and monomer.

In PEDOT:PSS, the degree of PEDOT:PSS concentration change over time can be determined using the absorbance peak at $550 \mathrm{~nm}$ and Beer-Lambert equation ${ }^{27}$ (eqn (1)):

$$
A=\varepsilon b c
$$

where $A$ is the absorbance, $\varepsilon$ is the absorption coefficient, $b$ is the distance that light travels through the material (the path length), and $c$ is the concentration of the absorbing species in the material. Since the absorbance of PEDOT:PSS at $550 \mathrm{~nm}$ is predominantly affected by PEDOT $^{28}$ the change in the concentration of PEDOT:PSS together with the time taken for absorbance can be thought of as the amount of EDOT used in the polymerization process. ${ }^{29,30}$ As a result, the EDOT-to-PEDOT polymerization rate can be calculated using UV-Vis-NIR data. ${ }^{31}$

Using these settings and equations, the actual reaction rate equation can be obtained by rearranging the actual experimental values listed in Table 1 .

The following equation was obtained by combining the rate and mole balance equations:

$$
-\frac{\mathrm{d} C_{\mathrm{A}}}{\mathrm{d} t}=k C_{\mathrm{A}}^{\mathrm{m}}
$$

By taking the natural logarithm of both sides of eqn (2), the following equation was obtained:

$$
\ln \left(-\frac{\mathrm{d} C_{\mathrm{A}}}{\mathrm{d} t}\right)=\ln k_{\mathrm{A}}+m \ln C_{\mathrm{A}}
$$

The reaction rate graph obtained using eqn (3) and the experimental values are given in Table 1 are shown in Fig. 1 . The slope of the graph denotes the order of the reaction $(m)$ and the $y$-intercept represents $\ln k$. The value of $k$ could therefore be determined.

The reaction rate could be expressed as follows:

$$
r_{\mathrm{A}}=\left(8.6 \times 10^{-3}\right) C_{\mathrm{A}}^{0.3039}
$$

This reaction is a 0.3039 -order reaction and is affected by the EDOT concentration. This means that the initial reaction rate 
Table 1 Relative and experimental concentration of EDOT, as determined using the UV-Vis-NIR data

\begin{tabular}{llllllcrcr}
\hline Time & $0 \mathrm{~h}$ & $2 \mathrm{~h}$ & $4 \mathrm{~h}$ & $6 \mathrm{~h}$ & $8 \mathrm{~h}$ & $10 \mathrm{~h}$ & $12 \mathrm{~h}$ & $15 \mathrm{~h}$ & $18 \mathrm{~h}$ \\
\hline Absorbance & 0 & 0.1023 & 0.2105 & 0.3230 & 0.4473 & 0.5339 & 0.6098 & 0.7261 & 0.7482 \\
Relative EDOT concentrate $(\mathrm{M})$ & 1 & 0.8632 & 0.7186 & 0.5682 & 0.4021 & 0.2864 & 0.1850 & 0.0295 & 0 \\
Experimental monomer $(\mathrm{EDOT})$ & 0.0405 & 0.0349 & 0.0291 & 0.0230 & 0.0162 & 0.0116 & 0.0074 & 0.0011 & 0 \\
$\begin{array}{l}\text { concentrate }\left(\left(C_{\mathrm{a}}\right)\left(\mathrm{mol} \mathrm{L}^{-1}\right)\right) \\
-\mathrm{d} C_{\mathrm{a}} / \mathrm{d} t\end{array}$ & 0.0027 & 0.0029 & 0.0030 & 0.0040 & 0.0027 & 0.0024 & 0.0020 & 0.0010 & 0
\end{tabular}

decreased when polymerization was performed by reducing the concentration to $1 / 2$ or $1 / 3$ due to the controlled addition process.

The activation energy of the EDOT polymerization reaction does not decrease with an increase in the catalyst concentration. $^{32}$ However, an increase in the catalyst concentration results in an increase in the rate constant because the catalyst and reactant interact with each other in the solution to increase the probability of polymerization..$^{33}$ Therefore, in a conventional batch-type polymerization, the catalyst concentration is proportional to the polymerization rate.

The experiment was performed under low-temperature isothermal conditions because the reaction rate constant $k$, which affects the polymerization reaction rate, ${ }^{34}$ is also affected by temperature. The following Arrhenius equation can be used: $:^{33,35}$

$$
K_{\mathrm{A}}(T)=A \mathrm{e}^{-E_{\mathrm{a}} / R T}
$$

where $A$ is the frequency factor (same units as rate constant $k$ ), $E_{\mathrm{a}}$ is the activation energy (cal $\mathrm{mol}^{-1}$ ), $R$ is the gas constant (1.987 cal $\left.\mathrm{mol}^{-1} \cdot \mathrm{K}^{-1}=8.3141 \mathrm{~J} \mathrm{~mol}^{-1} \mathrm{~K}^{-1}\right)$, and $T$ is the temperature $(\mathrm{K})$.

From eqn (5), it is evident that as the temperature is reduced, the reaction slows down. Therefore, in this study, the reaction was performed at $10{ }^{\circ} \mathrm{C}$ (melting point of EDOT), which is the lowest temperature possible for the liquid phase polymerization of EDOT.

These conditions make it possible to control the initial polymerization rate. If the amounts of the monomers and the

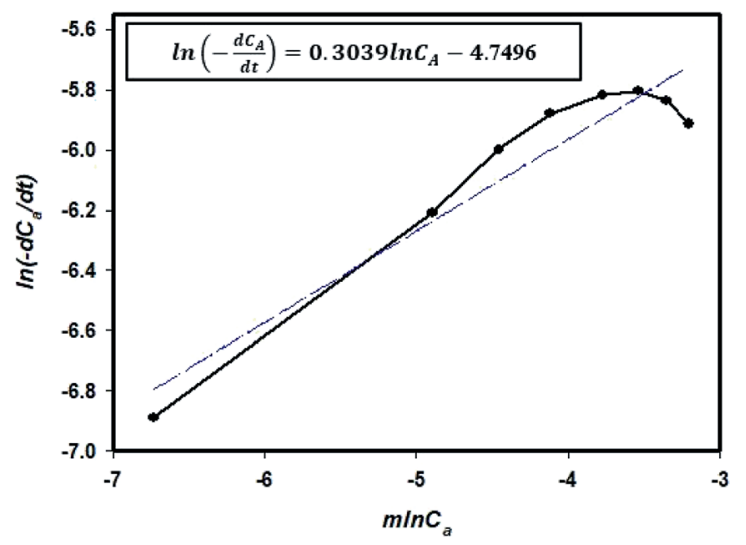

Fig. 1 Reaction graph obtained using eqn (3) and the experimental data (Table 1). catalyst used in the initiation are divided two or three times, the initial reaction rate becomes low. Therefore, it is possible to make a linear polymer at the initial stage of polymerization and increase the degree of polymerization of PEDOT through secondary and tertiary initiation (Scheme 2).

\section{Applying process based on conversion time}

In this process, the monomer and catalyst amounts were divided (by $1 / n$ of the total amount required during batch processing where $n$ is the number of divides) into small portions and were added in two and three steps (Scheme 1).

Using $r_{\mathrm{A}}$ obtained from eqn (4), we obtain:

$$
t=\frac{X C_{\mathrm{A} 0}}{\left(8.6 \times 10^{-3}\right) C_{\mathrm{A}}{ }^{0.3039}}
$$

where $X$ denotes the conversion of EDOT (reacted EDOT relative to the input EDOT), which is determined as follows:

$$
X=\frac{\text { moles of A reacted }}{\text { moles of A fed }}
$$

From this equation, it is evident that the EDOT concentration and conversion rate are correlated. As a result, the conversion completion time decreases as the initial EDOT concentration decreases, indicating that EDOT and the catalyst can be divided into time points.

In order to divide the reactants, we had to consider the input interval. Therefore, it was necessary to measure the time required for the complete conversion of EDOT in the batch process. ${ }^{36}$ Since PEDOT:PSS is dark blue in color and absorbs light in the visible region (550 nm), its absorbance in terms of the synthesis time was confirmed by UV-Vis-NIR spectroscopy. It was determined that saturation occurred after $18 \mathrm{~h}$, confirming the completion of the conversion (Fig. 2(a and c)). These results are represented as relative values based on the Beer-Lambert theory (Fig. 2(b) and eqn (1)). Based on this time, the monomer and catalyst were divided by 2 (two steps) and 3 (three steps) of their total amounts after every $8 \mathrm{~h} 30 \mathrm{~min}$ and $5 \mathrm{~h} 30 \mathrm{~min}$, respectively. Monomer and catalyst were added $30 \mathrm{~min}$ before the end of the ongoing reaction so that the monomers could be added to the PEDOT chain.

\section{Structure of PEDOT:PSS polymerized by CAP}

We used Raman spectroscopy to verify the increased linearity of PEDOT in the controlled addition process (Fig. 3). The controlled addition-polymerized PEDOT:PSS film exhibited vibration modes corresponding to asymmetric $\mathrm{C}_{\alpha}=\mathrm{C}_{\beta}$ 

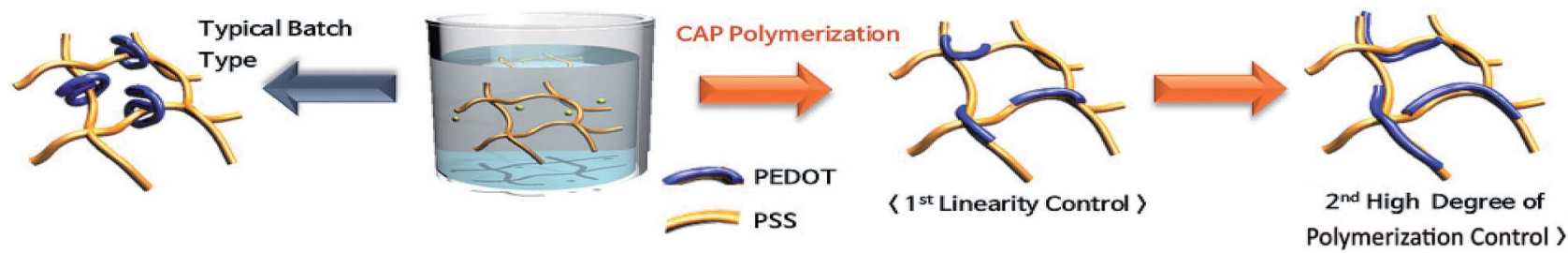

Scheme 2 Polymerization diagram of PEDOT:PSS by controlled addition process (CAP).

$\left(1530 \mathrm{~cm}^{-1}\right)$, symmetric $\mathrm{C}_{\alpha}=\mathrm{C}_{\beta}\left(1440 \mathrm{~cm}^{-1}\right)$, symmetric $\mathrm{C}_{\beta}-\mathrm{C}_{\beta}$ $\left(1370 \mathrm{~cm}^{-1}\right)$, and $\mathrm{C}_{\alpha}-\mathrm{C}_{\alpha}$ stretching vibration of the pentagonal rings of PEDOT $\left(1270 \mathrm{~cm}^{-1}\right)$. The shift of the peak at 1441 to $1430 \mathrm{~cm}^{-1}$ suggests that the PEDOT chain experienced a benzoid (coil)-to-quinoid (linear or expanded-coil) structural transition. ${ }^{37-40}$ It can be confirmed that the initial polymerization rate is slowed and the PEDOT can be slowly polymerized linearly.
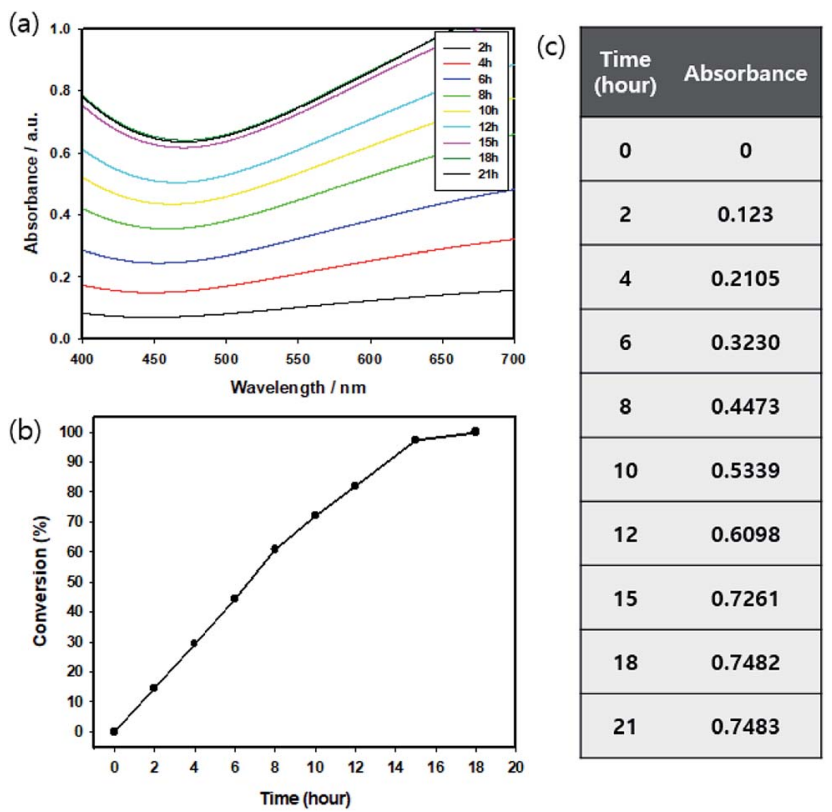

Fig. 2 (a) Absorption analysis of PEDOT:PSS for polymerization time, (b) relative conversion and (c) absolute absorbance (at $550 \mathrm{~nm}$ ).

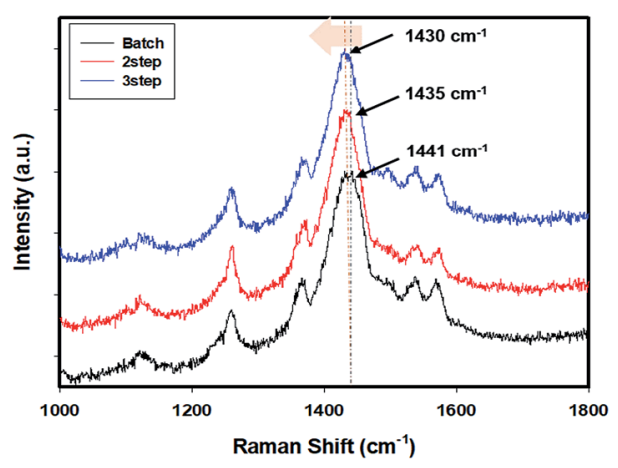

Fig. 3 Raman spectra of the PEDOT:PSS films prepared by the batch and controlled addition processes (under the excitation of a $632.8 \mathrm{~nm}$ $\mathrm{He}-\mathrm{Ne}$ laser).
XPS was used to analyze the chemical composition of the PEDOT:PSS films (Fig. 4). The films exhibited two peaks corresponding to PEDOT and PSS. PEDOT and PSS showed different chemical bonds with sulfur. The peak at $163.5-165.5 \mathrm{eV}$ corresponds to the sulfur atoms of PEDOT, while the peak at 168$169 \mathrm{eV}$ can be attributed to the sulfur atoms of PSS..$^{39,41,42}$ We compared the PEDOT content in the PEDOT:PSS chain with graphs normalized to the peaks for the sulfur atoms of PSS. As a result, according to increasing the intensity of the peak for the sulfur atoms of PEDOT, the number of PEDOT chains increased with an increase in the number of divisions in the PEDOT:PSS obtained through the controlled addition process for the same amount of PSS.

The structure of the controlled addition-polymerized PEDOT:PSS film was analyzed based on its degree of crystallization, as determined from XRD measurements (Fig. 5). The PEDOT:PSS film exhibited four peaks at $2 \theta=3.8^{\circ}(23 \AA), 6.6^{\circ}$ $(13.4 \AA), 17.7^{\circ}(5 \AA)$, and $25.6^{\circ}(3.5 \AA) .^{43,44}$ The peaks at $2 \theta=3.8^{\circ}$ and $6.6^{\circ}$ correspond to the lamella stacking distance $d(100)$ from PEDOT to PSS. The peaks at $2 \theta=17.7^{\circ}$ and $25.6^{\circ}$ correspond to the amorphous halo of PSS and $\pi-\pi$ stacking $(d 010)$ of the PEDOT thiophene ring, respectively. ${ }^{41,45}$ The linearity and packing property of the polymer improved with an increase in the number of divisions. In the case of the peak at $2 \theta=3.8^{\circ}$, the distance between the structures increased with an increase in the number of divisions. In addition, the sharpness of the peaks increased gradually, indicating the formation of an expanded structure or a linear conformation. The crystallinity of the PEDOT:PSS film also increased. The peak at $2 \theta=25.6^{\circ}$ indicates that the packing of the polymer formed by the controlled

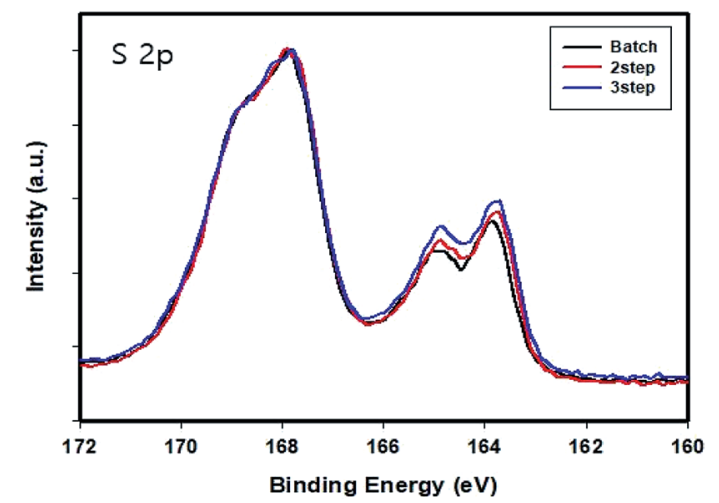

Fig. $4 \mathrm{~S}(2 \mathrm{p})$ XPS spectra of the PEDOT:PSS films normalized to the peaks of the sulfur atoms present in PSS. 


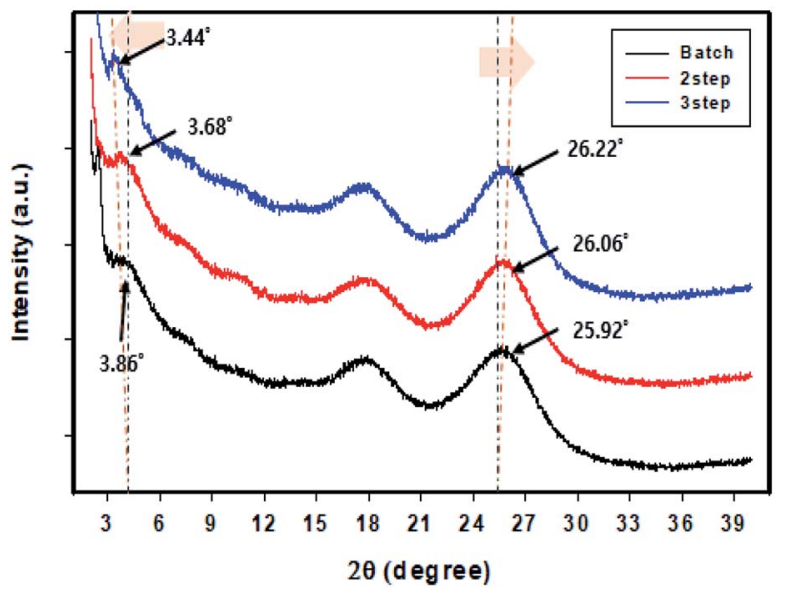

Fig. 5 XRD patterns of the PEDOT:PSS films prepared by the batch and controlled addition processes.

addition process was better than that of the polymer formed by the batch process. The diffraction angle increased with an increase in the number of divisions. An increase in the peak intensity suggests an increase in the crystallinity of the film.

\section{Electrical and optical properties of PEDOT:PSS}

The linear structure of PEDOT:PSS could be controlled by changing its polymerization process from batch to controlled addition. This also improved its electrical conductivity and sheet resistance. Polymerized PEDOT:PSS solution exhibits an electrical conductivity of less than $1 \mathrm{~S} \mathrm{~cm}^{-1}$ unless the phase separation is performed using organic solvents such as DMSO, DMF, etc. For this reason, DMSO, which is the most effective organic solvent for phase separation was used in this study. ${ }^{46,47}$ The surface resistance and electrical conductivity of PEDOT:PSS were also measured by adding a surfactant so that PEDOT:PSS could adhere to the substrate. The electrical conductivity of the film was determined by measuring its thickness and sheet resistance (Fig. 6(a)). ${ }^{48,49}$ As a result, this parameter increased to 557 and $623 \mathrm{~S} \mathrm{~cm}^{-1}$ for the PEDOT:PSS film when the polymerization was performed using the controlled addition process compared to the electric conductivity of $446 \mathrm{~S} \mathrm{~cm}^{-1}$ that was obtained using batch processing (Fig. 6(b)). This is because an increase in PEDOT length attached to the PSS chain (during its division) allows for a sufficient polymerization time. As a result, the film polymerized by the controlled addition process exhibited a larger conductive portion (PEDOT) than the film polymerized by the batch process.

After setting the surface resistivity of the films prepared in this study to $50-160 \Omega \mathrm{sq}^{-1}$, we compared their sheet resistances as a function of transmittance using a colorimeter. We also compared their transmittance $v s$. surface resistance curves obtained at 50, 100, and $150 \mathrm{ohms}$. The transmittance increased in the order: batch processed film $<$ two-step-controlled addition film $<$ three-step-controlled addition film (Fig. 7). This suggests that the linear structure of PEDOT:PSS, resulting in an increase in light transmission. The linear PEDOT:PSS structure (a)

$$
\begin{aligned}
& \text { Conductivity }(\sigma)\left[\frac{S}{\mathrm{~cm}}\right] \\
= & \frac{1}{\operatorname{Resistivity}(\rho)[\mathrm{ohm} \times \mathrm{cm}]} \\
= & \frac{1}{\text { Sheet resistance }\left[\frac{\mathrm{ohm}}{\mathrm{sq}}\right] \times \text { Thickness }[\mathrm{cm}]}
\end{aligned}
$$

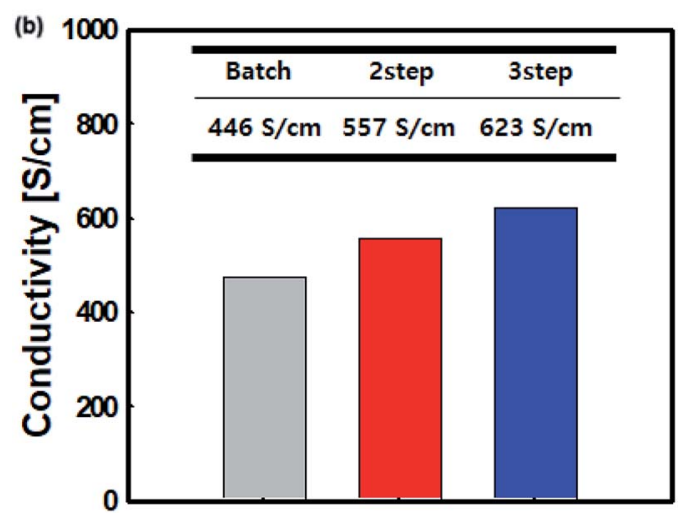

Fig. 6 (a) The electrical conductivity equation and (b) electrical conductivity of the PEDOT:PSS films prepared by the batch and controlled addition processes with $5 \%$ DMSO solution.

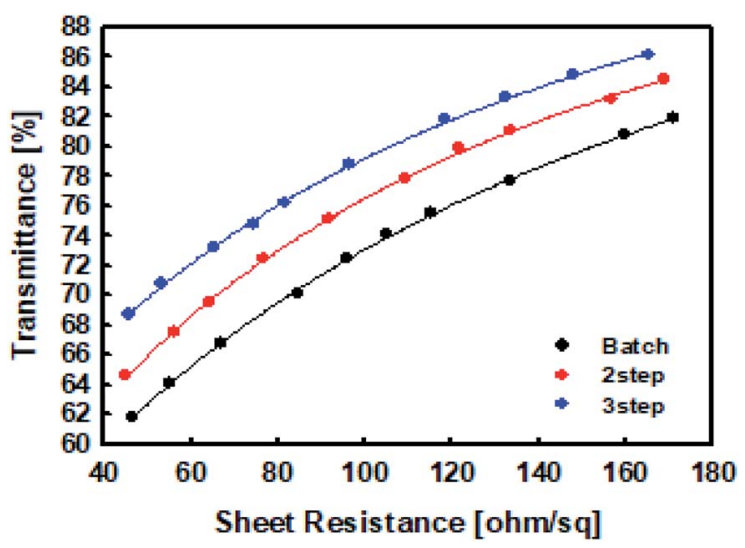

Fig. 7 The transmittance of the PEDOT:PSS films prepared by the batch and controlled addition processes.

lowers the intrinsic resistance to particles, and the longer PEDOT chains also lower the resistance, requiring less PEDOT:PSS particle for the same sheet resistance. ${ }^{15}$ As a result, the required PEDOT:PSS particle count is reduced in the same sheet resistance, resulting in increased transmittance.

\section{Conclusions}

In this study, we have improved the degree of linear PEDOT polymerization through modification of the polymerization process. We designed an experimental approach for the 
polymerization of PEDOT:PSS based on mathematical theory. The batch polymerization process used for the preparation of PEDOT:PSS was replaced with a controlled addition process, in which the initial polymerization rate was controlled by amount of monomer and catalyst. The total conversion time of the batch was $18 \mathrm{~h}$. The PEDOT:PSS was polymerized by dividing the monomer and catalyst two and three times after an interval of $8 \mathrm{~h} 30 \mathrm{~min}$ and $5 \mathrm{~h} 30 \mathrm{~min}$, respectively. Linear PEDOT was polymerized regularly by slowing the initial polymerization rate. The structure of the polymerized PEDOT:PSS was analyzed by Raman, XRD, XPS. Raman spectroscopy and XRD were used to confirm the increase in the linearity of the PEDOT polymerized using the controlled addition process. XPS used to confirm that the degree of polymerization of the PEDOT attached to PSS chain is improved. The increase in the amount of linearly polymerized PEDOT increased the electrical conductivity of the film by $39.68 \%$ ( 446 to $623 \mathrm{~S} \mathrm{~cm}^{-1}$ ) and optical property of the film by $6.2 \%$ ( 73 to $79.2 \%$ at $100 \mathrm{ohm}$ ). This process led to an increase in the PEDOT chain length and linearity to further improve electrical conductivity and transmittance at the same sheet resistance. We analyzed the improvement of the electrical and optical properties of PEDOT:PSS polymerized by the controlled addition process based on mathematical theory and experiments. These results will be useful as a process for polymerizing PEDOT:PSS with improved electrical and optical properties at an efficient process and price.

\section{Conflicts of interest}

There are no conflicts to declare.

\section{Acknowledgements}

This work was supported by the Nano Material Technology Development Program through the National Research Foundation of Korea (NRF) funded by the Ministry of Science, ICT \& Future Planning (MSIP, Korea) (NRF-2014M3A7B4050960/ 2014M3A7B4051745). This work was supported by the Technology Innovation Program (20002931) funded by the Ministry of Trade, Industry \& Energy (MOTIE, Korea).

\section{Notes and references}

1 D. Yoo, J. Kim and J. H. Kim, Nano Res., 2014, 7, 717-730.

2 S. Chen, L. Song, Z. Tao, X. Shao, Y. Huang, Q. Cui and X. Guo, Org. Electron., 2014, 15, 3654-3659.

3 J. Hwang, F. Amy and A. Kahn, Org. Electron., 2006, 7, 387396.

4 E. Ahlswede, W. Mühleisen, M. W. bin Moh Wahi, J. Hanisch and M. Powalla, Appl. Phys. Lett., 2008, 92, 143307.

5 D. Alemu Mengistie, P.-C. Wang and C.-W. Chu, J. Mater. Chem. A, 2013, 1, 9907.

6 V. Kostianovskii, B. Sanyoto and Y.-Y. Noh, Org. Electron., 2017, 44, 99-105.

7 C. K. Chiang, C. R. Fincher, Y. W. Park, A. J. Heeger, H. Shirakawa, E. J. Louis, S. C. Gau and A. G. MacDiarmid, Phys. Rev. Lett., 1977, 39, 1098-1101.
8 J. Wang, K. Cai, S. Shen and J. Yin, Synth. Met., 2014, 195, 132-136.

9 H. Ju and J. Kim, Chem. Eng. J., 2016, 297, 66-73.

10 R. Yue and J. Xu, Synth. Met., 2012, 162, 912-917.

11 T. Cheng, Y.-Z. Zhang, J.-P. Yi, L. Yang, J.-D. Zhang, W.-Y. Lai and W. Huang, J. Mater. Chem. A, 2016, 4, 13754-13763.

12 S. B. Singh, T. Kshetri, T. I. Singh, N. H. Kim and J. H. Lee, Chem. Eng. J., 2019, 359, 197-207.

13 Y.-H. Liu, J.-L. Xu, S. Shen, X.-L. Cai, L.-S. Chen and S.-D. Wang, J. Mater. Chem. A, 2017, 5, 9032-9041.

14 Z. Li, G. Ma, R. Ge, F. Qin, X. Dong, W. Meng, T. Liu, J. Tong, F. Jiang, Y. Zhou, K. Li, X. Min, K. Huo and Y. Zhou, Angew. Chem., Int. Ed., 2016, 55, 979-982.

15 H. Cho, W. Cho, Y. Kim, J.-g. Lee and J. H. Kim, RSC Adv., 2018, 8, 29044-29050.

16 B. Shamieh, S. Obuchovsky and G. L. Frey, J. Mater. Chem. C, 2016, 4, 1821-1828.

17 F. Wang, X. Zhang, Y. Ma and W. Yang, Appl. Surf. Sci., 2018, 427, 1038-1045.

18 M.-Y. Shen, T.-Y. Huang, C.-H. Luo, Y.-C. Huang, Y.-H. Tsai, T.-L. Wang and H.-h. Yu, J. Chin. Chem. Soc., 2018, 65, 149155.

19 S. Timpanaro, M. Kemerink, F. J. Touwslager, M. M. De Kok and S. Schrader, Chem. Phys. Lett., 2004, 394, 339-343.

20 A. M. Nardes, M. Kemerink, M. M. de Kok, E. Vinken, K. Maturova and R. A. J. Janssen, Org. Electron., 2008, 9, 727-734.

21 K.-C. Chang, M.-S. Jeng, C.-C. Yang, Y.-W. Chou, S.-K. Wu, M. A. Thomas and Y.-C. Peng, J. Electron. Mater., 2009, 38, 1182-1188.

22 F. Louwet, L. Groenendaal, J. Dhaen, J. Manca, J. Van Luppen, E. Verdonck and L. Leenders, Synth. Met., 2003, 135-136, 115-117.

23 J. Ouyang, Displays, 2013, 34, 423-436.

24 N. Duraisamy, S.-J. Hong and K.-H. Choi, Chem. Eng. J., 2013, 225, 887-894.

25 J. P. Thomas and K. T. Leung, Adv. Funct. Mater., 2014, 24, 4978-4985.

26 K. Hong, S. Y. Yang, C. Yang, S. H. Kim, D. Choi and C. E. Park, Org. Electron., 2008, 9, 864-868.

27 P. W. Atkins and J. De Paula, Atkins' Physical chemistry, Oxford University Press, Oxford, New York, 8th edn, 2006.

28 T.-R. Chou, S.-H. Chen, Y.-T. Chiang, Y.-T. Lin and C.-Y. Chao, J. Mater. Chem. C, 2015, 3, 3760-3766.

29 R. Pacios, R. Marcilla, C. Pozo-Gonzalo, J. A. Pomposo, H. Grande, J. Aizpurua and D. Mecerreyes, J. Nanosci. Nanotechnol., 2007, 7, 2938-2941.

30 T. Ji, L. Tan, X. Hu, Y. Dai and Y. Chen, Phys. Chem. Chem. Phys., 2015, 17, 4137-4145.

31 C.-H. Wu, T.-M. Don and W.-Y. Chiu, Polymer, 2011, 52, 1375-1384.

32 S. S. Zumdahl, Chemistry, Brooks/Cole, Cengage Learning, Belmont, CA, 8th edn, 2010.

33 O. Levenspiel, Chemical reaction engineering, Wiley, New York, 3rd edn, 1999.

34 H. Hart, Organic chemistry: a short course, Houghton Mifflin, Boston, 12th edn, 2007. 
35 H. S. Fogler, Elements of chemical reaction engineering, Prentice Hall PTR, Upper Saddle River, N.J., 3rd edn, 1999.

36 E. Lucht, I. Rocha, E. S. Orth, I. C. Riegel-Vidotti and M. Vidotti, Mater. Lett., 2015, 149, 116-119.

37 J. Kim, C. Park, S. Im, H. Lee and J. H. Kim, $R S C$ Adv., 2019, 9, 4028-4034.

38 S. Sakamoto, M. Okumura, Z. Zhao and Y. Furukawa, Chem. Phys. Lett., 2005, 412, 395-398.

39 Y. Kim, W. Cho, Y. Kim, H. Cho and J. H. Kim, J. Mater. Chem. C, 2018, 6, 8906-8913.

40 C. Wang, K. Sun, J. Fu, R. Chen, M. Li, Z. Zang, X. Liu, B. Li, H. Gong and J. Ouyang, Adv. Sustainable Syst., 2018, 2, 1800085.

41 L. Ouyang, C. Musumeci, M. J. Jafari, T. Ederth and O. Inganas, ACS Appl. Mater. Interfaces, 2015, 7, 1976419773.

42 W. Kim, S. Kim, S. U. Chai, M. S. Jung, J. K. Nam, J. H. Kim and J. H. Park, Nanoscale, 2017, 9, 12677-12683.
43 A. Hu, L. Tan, X. Hu, L. Hu, Q. Ai, X. Meng, L. Chen and Y. Chen, J. Mater. Chem. C, 2017, 5, 382-389.

44 N. Kim, S. Kee, S. H. Lee, B. H. Lee, Y. H. Kahng, Y. R. Jo, B. J. Kim and K. Lee, Adv. Mater., 2014, 26, 2268-2272.

45 N. Kim, B. H. Lee, D. Choi, G. Kim, H. Kim, J. R. Kim, J. Lee, Y. H. Kahng and K. Lee, Phys. Rev. Lett., 2012, 109, 106405.

46 E. Yildirim, G. Wu, X. Yong, T. L. Tan, Q. Zhu, J. Xu, J. Ouyang, J.-S. Wang and S.-W. Yang, J. Mater. Chem. C, 2018, 6, 5122-5131.

47 S. H. Lee, J. S. Sohn, S. B. Kulkarni, U. M. Patil, S. C. Jun and J. H. Kim, Org. Electron., 2014, 15, 3423-3430.

48 R. Chang and J. W. Thoman, Physical chemistry for the chemical sciences, University Science Books, Mill Valley, California, 2014.

49 I. Popescu, E. Heracleous, Z. Skoufa, A. Lemonidou and I. C. Marcu, Phys. Chem. Chem. Phys., 2014, 16, 4962-4970. 